\title{
VISCERAL FAT VERSUS SUBCUTANEOUS FAT: COMPARISON OF THEIR ASSOCIATION WITH TYPE 2 DIABETES MELLITUS OK Shrestha ${ }^{1 *}$, GL Shrestha ${ }^{2}$
}

'Department of Radiology, Gandaki Medical College, Pokhara.

${ }^{2}$ Department of Radiology, Fishtail Hospital and Research Center Pvt. Ltd., Pokhara.

*Correspondence to: Om Kumar Shrestha, Department of Radiology, Gandaki Medical College, Pokhara. Email: shresthaom@gmail.com

\begin{abstract}
To compare abdominal visceral fat with subcutaneous fat in relation to their association with type 2 diabetes. Abdominal fat distribution was measured using Computed Tomography in 60 subjects (30 diabetics and 30 non-diabetics). Computed tomography images obtained at two intervertebral locations L2-L3 and L4-L5 were used to measure areas of total fat, visceral fat and subcutaneous fat using slice thickness of $5 \mathrm{~mm}$ and attenuation range of -190 to -30 Hounsfield units. Data were analyzed using logistic regression. At L2-L3 level, taking visceral fat and subcutaneous fat as predictor variables, diabetes was correctly classified at $78.0 \%$ and $66.10 \%$ respectively. At L4-L5 level, taking visceral fat and subcutaneous fat as predictor variables, diabetes was correctly classified at $72.88 \%$ and $67.80 \%$ respectively. Regardless of the measurement site, visceral fat has significantly stronger association with diabetes, compared to subcutaneous fat. Visceral fat at L2-L3 level alone may be a better predictor of diabetes. Abdominal fat distribution, visceral fat, subcutaneous fat, type 2 diabetes.
\end{abstract}

Key Words: Abdominal fat distribution, Subcutaneous fat, Type 2 diabetes, Visceral fat.

\section{INTRODUCTION}

In November 14, 2012, International Diabetes Federation published new data indicating the enormity of the diabetes epidemic. The number of people known to be affected worldwide has soared to 371 million in 2012 with global prevalence of $8.3 \%$ in adults. ${ }^{1}$ IDF also estimates that 187 million people $(50 \%)$ with diabetes are undiagnosed. Prevalence of diabetes in Nepal is 3.05\% (506.73 thousand adults). ${ }^{2}$ Number of adult with undiagnosed diabetes in Nepal is estimated 1,120.3 thousands. Type 2 diabetes mellitus (T2DM) accounts for 90 to $95 \%$ of the incidence of diabetes. ${ }^{3}$ Although previously T2DM was predominantly diagnosed in middle-aged or older people, it has now begun to show up in teenagers and children.

Abdominal subcutaneous fat (SCF) is located immediately beneath the skin and on top of abdominal musculature. Visceral fat (VF) is located in the body cavity beneath the abdominal muscles. VF depots are composed of the greater omentum, lesser omentum and the mesenteric fat. A lesser amount of $\mathrm{VF}$ is located retroperitoneally. In general, VF accounts for $10-20 \%$ of total fat (TF) in men and 5-8\% in women. ${ }^{4,5} \mathrm{SCF}$ accounts for about $80 \%$ of TF. ${ }^{5}$

Obesity is probably the most powerful predictor in development of T2DM. ${ }^{6}$ Increasing evidence has accumulated to demonstrate that regional adiposity plays a greater role in development of diabetes and impaired glucose tolerance than generalized obesity. While abdominal obesity is determined by the accumulation of both SCF and VF, the excess accumulation of VF appears to play a more significant pathogenic role. ${ }^{4,7-13}$ Compared to SCF, VF is much more strongly linked to insulin resistance and T2DM. ${ }^{4,7-10,14}$ However, controversy still exists regarding the contribution of subcutaneous and visceral fat in the development of diabetes. Some have reported both contributing to insulin resistance in T2DM. ${ }^{15-18}$ Others have documented that VF is associated with an increased incidence of metabolic syndrome and has significantly stronger relation with insulin resistance and diabetes. ${ }^{7-10,14,19} \mathrm{SCF}$ is not consistently reported to be a significant correlate of metabolic syndrome or its individual component. However, some ${ }^{20-24}$ studies have shown associations between SCF, insulin resistance and diabetes. This study aims to compare VF with SCF regarding their association with T2DM.

\section{RESEARCH DESIGN AND METHODS}

This prospective correlational study was carried out in Gandaki Medical College with study sample consisting of 60 subjects between 20 and 70 years of age. Among them 30 were diabetics (male18; female12) and 30 were non-diabetics (male15; female15). The diabetic subjects were selected from a cohort of people with known T2DM who received abdominal Computed Tomography (CT) scan in Gandaki Medical College. Inclusion criteria for diabetic subjects were age between 20 to 75 years, T2DM and no severe chronic diabetic complications. Nondiabetic subjects were selected at the same hospital, from the cohort of people who had received an abdominal CT scan for examination of lumbar spine. Those with any apparent health problem except mild lumbar spine degeneration were excluded. 
Height and weight were measured in all subjects before proceeding to CT scanning and the body mass indices [BMI = weight in $\mathrm{kg} /(\text { height in } \mathrm{m})^{2}$ ] were calculated.

Abdominal fat distribution was measured in all subjects by CT using a TOSHIBA ASTEION 4 slice CT scanner. Subjects were examined in supine position with both arms stretched above the head. An initial scan was taken from a lateral view to establish the bony landmarks on a radiograph of the skeleton as a reference. Contiguous transverse images were acquired from vertebral body L2 to vertebral body L5. The scan was performed at $120 \mathrm{kV}$ and $150 \mathrm{~mA}$ with a $5 \mathrm{~mm}$ slice thickness. For each subject, an axial image obtained at midway between L2 and L3, and another one at midway between L4 and L5 were identified for measuring abdominal fat. TF area was estimated by demarcating the whole abdomen scan with a computerized pen and calculating the contained adipose tissue using an attenuation range of -190 to -30 Hounsfield Units (Fig. 1). Cross-sectional VF area was calculated by applying the same attenuation range and delineating the inner margin of the abdominal musculature surrounding the abdominal cavity. SCF area was determined by delineating the outer margin of the abdominal musculature using same method and subtracting the obtained area from the TF area. Statistical analyses were performed using STATA version 9.1. Group data are presented as means \pm SD. Comparison between VF and SCF regarding their association with diabetes was done using logistic regression analysis adjusted for age, sex and BMI.

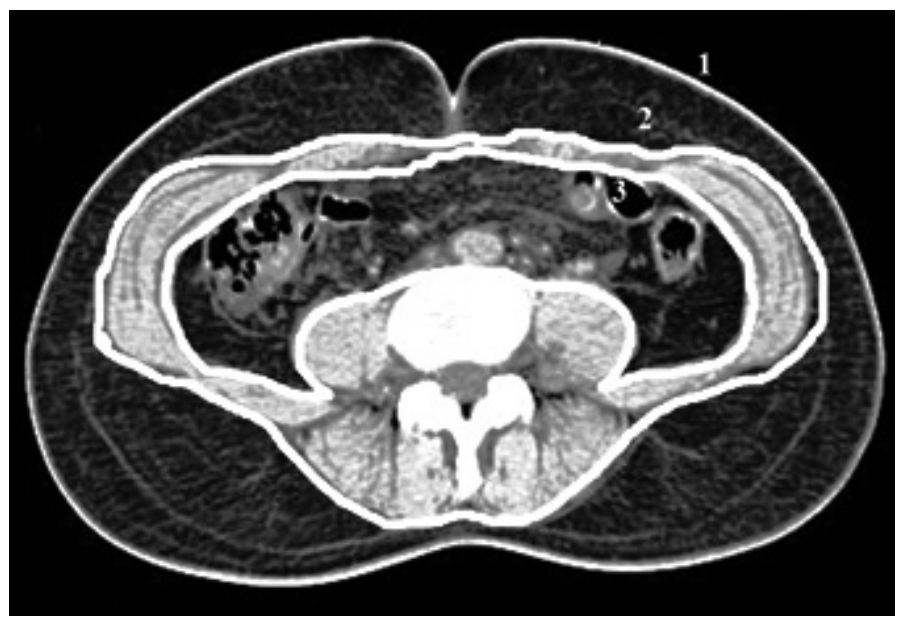

Figure 1. Illustration of method for determining abdominal fat distribution on a CT image scanned at L4-L5 plane.

$\mathrm{TF}=$ Fat area within perimeter 1

$\mathrm{VF}=$ Fat area within perimeter 3

$\mathrm{SCF}=$ Fat area within perimeter 1 minus fat area within perimeter 2

\section{RESULTS}

Subject characteristics are listed in Table 1. Mean values of BMI, $\mathrm{TF}$ area and VF area were highest in diabetic men. Irrespective of sex and diabetic status, mean values of TF area and SCF area were higher at L4-L5 level. Likewise, Irrespective of sex and diabetic status, mean value of VF area was higher at L2L3 level. In men, TF, VF and SCF were higher in diabetic men irrespective of the measurement site. In women, TF and SCF were higher in non-diabetics while VF was higher in diabetics irrespective of measurement site. Increased BMI was noted in diabetic men while BMI was normal with non-diabetics and diabetic women.
Table 1: Baseline characteristics of 60 subjects; Data are means \pm SD

\begin{tabular}{|c|c|c|}
\hline & Diabetics $(n=30)$ & $\begin{array}{l}\text { Nondiabetics } \\
(\mathrm{n}=30)\end{array}$ \\
\hline \multicolumn{3}{|l|}{ MALE } \\
\hline $\mathbf{n}$ & 18 & 15 \\
\hline Age (years) & $50.17 \pm 10.1$ & $44.7 \pm 14.08$ \\
\hline BMI $\left(\mathrm{kg} / \mathrm{m}^{2}\right)$ & $26.11 \pm 3.83$ & $24.23 \pm 2.6$ \\
\hline TF area L2-L3 $\left(\mathrm{cm}^{2}\right)$ & $322.82 \pm 110.29$ & $233.74 \pm 96.46$ \\
\hline TF area L4-L5 $\left(\mathrm{cm}^{2}\right)$ & $339.69 \pm 126.2$ & $239.2 \pm 87.34$ \\
\hline VF area L2-L3 $\left(\mathrm{cm}^{2}\right)$ & $196.62 \pm 58.57$ & $129.48 \pm 68.35$ \\
\hline VF area L4-L5 $\left(\mathrm{cm}^{2}\right)$ & $155.65 \pm 62.38$ & $86.66 \pm 37.39$ \\
\hline $\mathrm{SCF}$ area L2-L3 $\left(\mathrm{cm}^{2}\right)$ & $113.48 \pm 54.42$ & $91.56 \pm 30.15$ \\
\hline $\mathrm{SCF}$ area L4-L5 $\left(\mathrm{cm}^{2}\right)$ & $175.46 \pm 82.77$ & $133.45 \pm 51.17$ \\
\hline \multicolumn{3}{|l|}{ FEMALE } \\
\hline $\mathbf{n}$ & 12 & 15 \\
\hline Age (years) & $55.0 \pm 7.36$ & $47.75 \pm 12.7$ \\
\hline BMI $\left(\mathrm{kg} / \mathrm{m}^{2}\right)$ & $23.877 \pm 2.14$ & $23.92 \pm 2.25$ \\
\hline TF area L2-L3 $\left(\mathrm{cm}^{2}\right)$ & $255.23 \pm 58.2$ & $260.56 \pm 86.8$ \\
\hline $\mathrm{TF}$ area L4-L5 $\left(\mathrm{cm}^{2}\right)$ & $300.43 \pm 84.4$ & $334.37 \pm 87.55$ \\
\hline VF area L2-L3 $\left(\mathrm{cm}^{2}\right)$ & $125.13 \pm 42.71$ & $107.38 \pm 43.27$ \\
\hline VF area L4-L5 $\left(\mathrm{cm}^{2}\right)$ & $105.02 \pm 44.87$ & $97.19 \pm 32.26$ \\
\hline $\mathrm{SCF}$ area L2-L3 $\left(\mathrm{cm}^{2}\right)$ & $118.36 \pm 26.96$ & $136.91 \pm 47.42$ \\
\hline SCF area L4-L5 $\left(\mathrm{cm}^{2}\right)$ & $182.09 \pm 58.33$ & $218.62 \pm 60.61$ \\
\hline
\end{tabular}

Associations of VF and SCF with diabetes are shown in Table 2 as correctly classified percent values computed using logistic regression with VF and SCF areas as predictor variables for diabetes. This analysis was adjusted for age, sex and BMI. Irrespective of the measurement site, VF had significantly higher correctly classified value for predicting diabetes than SCF. VF area measured at L2-L3 correctly classified diabetes at a higher percent than at L4-L5. For SCF areas, correctly classified percent values obtained at L2-L3 and L4-L5 were not significantly different. 
Table 2. Correctly classified values for diabetes with respect to $\mathrm{VF}$ and SCF areas as the predictor variables.

\begin{tabular}{|c|c|c|}
\hline \multirow{2}{*}{$\begin{array}{l}\text { Predictor } \\
\text { variable }\end{array}$} & \multicolumn{2}{|c|}{ Diabetes correctly classified } \\
\hline & L2-L3 & L4-L5 \\
\hline VF & $\begin{array}{l}\mathbf{7 8 . 0} \% \\
\text { sensitivity }=82.76 \% \\
\text { specificity }=73.33 \%\end{array}$ & $\begin{array}{l}\mathbf{7 2 . 8 8} \% \\
\text { sensitivity }=68.97 \% \\
\text { specificity }=76.67 \%\end{array}$ \\
\hline SCF & $\begin{array}{l}\mathbf{6 6 . 1 0} \% \\
\text { sensitivity }=68.97 \% \\
\text { specificity }=63.33 \%\end{array}$ & $\begin{array}{l}\mathbf{6 7 . 8 0} \% \\
\text { sensitivity }=68.97 \% \\
\text { specificity }=66.67 \%\end{array}$ \\
\hline
\end{tabular}

Logistic regression analysis was adjusted for age, sex and BMI.

\section{DISCUSSION}

Visceral fat, being portally drained and lipolytically more active, ${ }^{10,25}$ is a powerful independent predictor of insulin resistance in T2DM. ${ }^{9,10,14,26}$ Many studies have documented that VF is associated with increased incidence of metabolic syndrome and has significantly stronger relation with insulin resistance and diabetes. ${ }^{7-10,14,19}$ Findings in this study corroborates with previous studies as this study (table 2) shows that visceral fat has a stronger association with development of diabetes compared to subcutaneous fat independent of measurement site.

It is as well reported that the greatest deposition of omental and mesenteric fat is located in the upper abdomen within the region between intervertebral locations L1-L2 and L3-L4 $4^{10,25,27}$ This study shows that there is greater amount of visceral fat at L2L3 level (table 1) which is in consistent with previous studies. Thus, visceral fat at L2-L3 level might be expected to have a stronger association with the development of diabetes than visceral fat at L4-L5 or subcutaneous fat at any measurement site. This observation is relevant to the findings in this study. An important finding of this study (Table 2) was that visceral fat at L2-L3 level was much more strongly associated with the development of diabetes than visceral fat at L4-L5 level which is the traditional landmark for measuring abdominal fat distribution. These findings can have important implications as it suggests that visceral fat at intervertebral location L2-L3 alone may be a better predictor of diabetes. This study also shows that greater deposition of TF and SCF lies at L4-L5.

There are limitations of this study that should be noted. The sample size is relatively small. In addition, there were only 4 obese subjects. Rest were either overweight or with normal BMI. A larger sample size and inclusion of more frankly obese subjects would be appropriate to confirm the results in this study.

\section{CONCLUSION}

While visceral fat has stronger association with diabetes compared with subcutaneous fat, visceral fat at L2-L3 level alone plays greater role in the development of type 2 diabetes. The findings may prove useful in understanding visceral and central obesity and may have relevance to clinical assessment, prevention and treatment of diabetes.

\section{REFERENCES}

1. International Diabetes Federation 2012. IDF DIABETES ATLAS UPDATE 2012. Accessed on 10 Jan 2013. Available from http://www.idf.org/diabetesatlas/5e/Update2012.

2. International Diabetes Federation 2012. Diabetes at a glance, 2012 South-East Asia (SEA). Accessed on 10 Jan 2013. Available from http://www.idf.org/sites/default/files/SEA_5E_ Update_Country.pdf

3. Cheng D. Prevalence, predisposition and prevention of type II diabetes. Nutrition and Metabolism 2005; 2: 29-32.

4. Freedland ES. Role of a critical visceral adipose tissue threshold (CVATT) in metabolic syndrome: implications for controlling dietary carbohydrates: a review. Nutrition \& Metabolism 2004; 1:12.

5. Wajchenberg BL. Subcutaneous and visceral adipose tissue: their relation to the metabolic syndrome. Endocr Rev 2000; 21:679-738.

6. Tuomilehto J, Lindstrom J, Silventoinen K. Obesity and prevention of type 2 diabetes. In Barnett AH \& Kumar S (Eds.), Obesity and Diabetes 2004; chap. 5: 79-97.

7. Kahn BB, Flier JS. Obesity and insulin resistance. J Clin Inves 2000; 106 (4): 473-481.

8. Waine C. Obesity and type 2 diabetes. Nutrition Bulletin 2006; 31 (2): 111-114.

9. Bonora E, Targher G, Alberiche M et al. Predictors of insulin sensitivity in Type 2 diabetes mellitus. Diabetic Medicine 2002; 19 (7): 535-542.

10. Kuk JL, Blair SN, Church TS, Ross R. Does measurement site for visceral and abdominal subcutaneous adipose tissue alter associations with the metabolic syndrome? Diabetes Care 2006; 29: 679-684.

11. Nicklas BJ, Penninx BWJH, Ryan AS, Berman DM, Lynch NA, Dennis KE. Visceral adipose tissue cutoffs associated with metabolic risk factors for coronary heart disease in women. Diabetes Care 2003; 26: 1413-1420.

12. McTernan P, Kumar S. Pathogenesis of obesity-related type 2 diabetes. In Barnett AH \& Kumar S (Eds.), Obesity and Diabetes 2004; chap. 4: 49-78.

13. Park YW, Allison DB, Heymsfield SB, Gallagher D. Larger amounts of visceral adipose tissue in Asian Americans. Obesity Research 2001; 9: 381-387.

14. Lebovitz HE. Insulin resistance - a common link between type 2 diabetes and cardiovascular disease. Diabetes, Obesity and Metabolism 2006; 8 (3): 237-249.

15. Albu JB, Kovera AJ, Johnson JA. Fat distribution and health in obesity. Ann N Y Acad Sci 2000; 904: 491-501.

16. Marcus MA, Murphy L, PI-Sunyer FX, et al. Insulin sensitivity and serum triglyceride level in obese white and black women: relationship to visceral and truncal subcutaneous fat. Metabolism 1999; 48: 194-9.

17. Bavenholm PN, Kuhl J, Pigon J et al. Insulin resistance in Type 2 diabetes: Association with truncal obesity, impaired fitness and atypical malonyl coenzyme a regulation. J Clin Endocrinol Metab 2003; 88: 82-7.

18. Yatagai T, Nagasaka S, Taniguchi A et al. Hypoadiponectinemia is associated with visceral fat accumulation and insulin resistance in Japanese men with type 2 diabetes mellitus. Metabolism 2003; 52: 1274-8.

19. Bjorntorp P. Portal adipose tissue as a generator of risk factors for cardiovascular disease and diabetes. Arteriosclerosis 
1990; 10: 493-6.

20. Abate N, Garg A, Pershock RM et al. Relationships of generalized and regional adiposity to insulin sensitivity in men with NIDDM. Diabetes 1996; 45: 1684-93.

21. Abate N, Garg A, Pershock RM et al. Relationships of generalized and regional adiposity to insulin sensitivity in men. J Clin Invest 1995; 96: 88-98.

22. Goodpaster BH, Thaete FL, Simoneau JA, et al. Subcutaneous abdominal fat and thigh muscle composition predict insulin sensitivity independently of visceral fat. Diabetes 1997; 46: 1579-85.

23. Kelley DE, Mandarino LJ. Fuel selection in human skeletal muscle in insulin resistance: a reexamination. Diabetes 2000; 49: 677-683.

24. Smith SR, Lovejoy JC, Greenway F et al. Contributions of total body fat, abdominal subcutaneous adipose tissue compartments, and visceral adipose tissue to the metabolic complications of obesity. Metabolism 2001; 50: 425-435.
25. Benthem L, Kuipers F, Steffens AB, Scheurink AJW. Excessive portal venous supply of long-chain free fatty acids to the liver, leading to hypothalamus-pituitary-adrenal-axis and sympathetic activation as a key to the development of syndrome $\mathrm{X}$ : a proposed concept for the induction of syndrome X. Annals of the New York Academy of Sciences 1999; 892: 308-311.

26. Bosello O, Zamboni M. Visceral obesity and metabolic syndrome. Obesity Reviews 2000; 1 (1): 47-56.

27. Abate N, Garg A, Coleman R, Grundy SR, Peshock RM. Prediction of total subcutaneous abdominal, intraperitoneal, and retroperitoneal adipose tissue masses in men by a single axial magnetic resonance imaging slice. Am J Clin Nutr 1997; 65: 403-408. 